\title{
A Prospective Study on the Relationship Between Cervical Dilatation at Initial Presentation in Labour and Subsequent Outcome in Nulliparous Women
}

\author{
Smriti Kona Kabiraj ${ }^{1}$ \\ Juthi Bhowmik ${ }^{2}$ \\ Haradhan Deb Nath ${ }^{3 *}$
}

'Department of Physiology

Government Homeopathic Medical College Dhaka, Bangladesh.

${ }^{2}$ Department of Gynae \& Obstetrics Ad-din Medical College

Dhaka, Bangladesh.

${ }^{3}$ Department of Neurosurgery Bangabandhu Sheikh Mujib Medical University Dhaka, Bangladesh.
*Correspondence to:

\section{Dr. Haradhan Deb Nath}

Department of Neurosurgery Bangabandhu Sheikh Mujib Medical University Dhaka, Bangladesh.

Mobile: +8801711354120

E-mail: dr.haradhan@yahoo.com

\begin{abstract}
Background: The spontaneous birth of a live infant can convey a huge degree of both satisfaction and achievement for both the mother and her partner. Many factors influence the variation in rates of caesarean section among hospitals throughout the world. These included patients' demographic characteristics, underlying medical and obstetric complication, hospital facilities, hospital practice and physician practice style. Objective: The present study was planned to determine how the outcome of women change with timing of admission either in active or latent phase of spontaneous labour. Methods: This was a prospective observational study, which was conducted at labour ward, department of Obstetrics and Gynaecology, BSMMU hospital and DMCH Dhaka, from February 1, 2008 to August 30, 2008, where data were collected prospectively. Patients with any medical or obstetric complications, rupture of membrane antenatally diagnosed fetal anomalies or death and with prior caesarean section were excluded from the study. Patients with cervical dilatation at less than $4 \mathrm{~cm}$ were in group I. On the other hand, patients with cervical dilatation of $4 \mathrm{~cm}$ or more in active phase and these types of patients were allocated in group II. Results: Outcome differences were compared using chi-square(X2) test, fishers exact test, A 'p' value $<0.05$ considered significant. Main outcome variables were duration of labour, mode of delivery, indication for caesarean section, need for oxytocin, labour analgesia, Apgar score $<7$, maternal PPH and postpartum hospital stay. A total 500 patients were enrolled during the study period. Of them 308 patients were $(61.6 \%)$ in group I and 192 patients $(38.4 \%)$ in group II. Dystocia was the main indication for caesarean delivery in early admitted group which was $58.6 \%$ and fetal distress in late admitted group which was $37.5 \%$. Second commonest indication for caesarean section was fetal distress which was $31.6 \%$ in group I and dystocia $50.0 \%$ in group II). Oxytocin for augmentation was used in $70.0 \%$ in group I and $30.0 \%$ in group II. Conclusion: It is shown that early admission to the hospital in low-risk women may negatively affect the outcome of labour and are at increased risk of prolonged labour, more oxytocin used, increased rate of caesarean section.
\end{abstract}

Key words: Labour; nulliparous; cervical dilatation.

\section{INTRODUCTION}

Labour is a sequence of uterine contractions that results in effacement and dilatation of the cervix and voluntary bearing-down efforts leading to the expulsion pervagina of the product of conception ${ }^{1}$. Cervimetry has become accepted as the first measure of progress of labour because it is simple to comprehend, easy to measure, reproducible and subject to little observer error ${ }^{2}$. Nature of cervical dilatation indicates the outcome of labour. A previous study reports that cervical dystocia is one of the most important indications of caesarean section ${ }^{3}$.

It is difficult for a pregnant woman to manage timing of presentation to the hospital admission specially a nulliparous one when she is in labour. A previous study has shown that women who present to hospital at $0-3 \mathrm{~cm}$ spend less time in labour before presentation and are more likely to have obstetric intervention than those presenting in more advanced labour ${ }^{4}$. 
Those patients who attend earlier are usually in their latent phase of labour which may be a prolonged one resulted in a prolonged labour although their active phase is not prolonged. Thus the overall incidence of interference increases in that cases $^{5}$. This study was carried out to find out the outcome of labour in the study population and also to ascertain the condition of the newborn.

\section{MATERIALS \& METHODS}

It was a prospective observational study carried out at Department of Obstetrics and Gynaecology in Bangabandhu Sheikh Mujib Medical University (BSMMU) hospital and Dhaka Medical College Hospital (DMCH), Dhaka during the period from February 1, 2008 to August 30, 2008. Total 500 primi patients admitted with labour pain either in latent or active phase were selected for evaluation. Group I: Cervical dilatation (os) $<4 \mathrm{~cm}$ comprises 308 patients and Group II: Cervical dilatation (os) $\geq 4 \mathrm{~cm}$ comprises 192 patients.

Data was collected in pre-designed sheet which is shown in appendix. Statistical analysis was performed by computer based SPSS (Statistical Package for social science) software. Data were compared by relevant test. A p value $<0.05$ is consider statistically significant.

After admission, full history was taken and general \& obstetrics examination was done whether intact or rupture. Cervical dilation will express in centimeters $(10 \mathrm{~cm}$ when fully dilate). It was measured with fingers but was recorded in $\mathrm{cm}$. One finger equals to $1.6 \mathrm{~cm}$ on average. If the progress of labour was not satisfactory due to weak uterine contractions, acceleration of labour was done by oxytocin, All cases was monitor by closed and careful clinical observation to ensure correct management. Course of labour was observed regarding the duration of labour, augmentation with oxytocin and mode of delivery in each and every case. The labour was said to be prolonged when the combined duration of $1^{\text {st }}$ and $2^{\text {nd }}$ stage of labour was more than the arbitrary time limit of 18 hours.

\section{RESULTS}

Age ranged from $<19->35$ years and shows no significant difference between two groups (Table 1). Socio-economic status in two groups was also similar (Table 2).

Table 1: Age distribution of the patients $(n=500)$.

\begin{tabular}{lcccccc} 
Characteristics & \multicolumn{2}{c}{ Group I $(\mathrm{n}=308)$} & \multicolumn{2}{c}{ Group II $(\mathrm{n}=192)$} & $\mathrm{t}$ value & P value \\
& No. & $\%$ & No. & $\%$ & & \\
$\leq 19$ & 66 & 21.4 & 24 & 12.6 & & \\
$20-24$ & 161 & 52.2 & 108 & 56.3 & & \\
$25-29$ & 60 & 19.5 & 36 & 18.8 & & \\
$30-34$ & 21 & 6.8 & 12 & 6.2 & & \\
$\geq 35$ & 0 & 00 & 12 & 6.3 & & \\
Mean \pm SD & $22.3 \pm 3.4$ & $23.6 \pm 4.6$ & 3.61 & $0.001 \mathrm{~S}$
\end{tabular}

$s=$ significant; $p$ value reached from unpaired ' $t$ ' test
Table 2: Socio economic condition of the patients $(n=500)$

\begin{tabular}{|c|c|c|c|c|c|c|}
\hline \multirow[t]{2}{*}{$\begin{array}{l}\text { Socio economic } \\
\text { condition }\end{array}$} & \multicolumn{2}{|c|}{$\begin{array}{l}\text { Group I } \\
(n=308)\end{array}$} & \multicolumn{2}{|c|}{$\begin{array}{l}\text { Group II } \\
(\mathrm{n}=192)\end{array}$} & \multirow{2}{*}{$\begin{array}{c}\text { Chi } \\
\text { value } \\
\%\end{array}$} & \multirow[t]{2}{*}{$\mathrm{p}$ value } \\
\hline & $\mathrm{n}$ & $\%$ & & $\mathrm{n}$ & & \\
\hline \multirow[t]{2}{*}{ Lower class } & 166 & 53.9 & 120 & 62.5 & & \\
\hline & & & & & 8.36 & $0.015 \mathrm{~S}$ \\
\hline Middle class & 98 & 31.8 & 60 & 31.3 & & \\
\hline Higher class & 44 & 14.3 & 12 & 6.3 & & \\
\hline
\end{tabular}

$\mathrm{S}=$ significant; $\mathrm{p}$ value reached from Chi square test

Table 3: Gestational age of the patients $(n=500)$

\begin{tabular}{lcccccc}
$\begin{array}{l}\text { Gestational } \\
\text { age (wks) }\end{array}$ & \multicolumn{2}{c}{$\begin{array}{c}\text { Group I } \\
(\mathrm{n}=308)\end{array}$} & \multicolumn{2}{c}{ Group II } & T value & P value \\
& $\mathrm{n}$ & $\%$ & $\mathrm{n}=192)$ & $\%$ & & \\
$37-38 \mathrm{wks}$ & 117 & 38.0 & 60 & 31.2 & & \\
$39-40$ wks & 158 & 51.3 & 102 & 53.2 & & \\
$41-42$ wks & 33 & 10.7 & 30 & 15.6 & & \\
Mean \pm SD & $39.1 \pm 1.16$ & $38.9 \pm 1.10$ & 1.936 & $0.059 \mathrm{NS}$ \\
\hline
\end{tabular}

$\mathrm{s}$ significant; $\mathrm{p}$ value reached from unpaired ' $\mathrm{t}$ ' test

Table 3 reveals that 39-40 weeks of gestation was predominant in both groups. The mean difference of pre-hospitalization duration was statistically significant $(\mathrm{p}<0.05)$ (Table 4$)$.

Table 4: Duration of lower abdominal pain before hospitalization $(n=500)$

\begin{tabular}{lcccccc}
$\begin{array}{l}\text { Socio economic } \\
\text { condition }\end{array}$ & \multicolumn{2}{c}{$\begin{array}{c}\text { Group I } \\
(\mathrm{n}=308)\end{array}$} & \multicolumn{2}{c}{$\begin{array}{l}\text { Group II } \\
(\mathrm{n}=192)\end{array}$} & $\begin{array}{c}\text { Chi } \\
\text { value }\end{array}$ & $\mathrm{p}$ value \\
& $\mathrm{n}$ & $\%$ & $\mathrm{n} \quad \%$ & & \\
2-6 hours & 57 & 18.5 & 42 & 21.9 & & \\
& & & & & & \\
$7-12$ hours & 138 & 44.8 & 48 & 25.0 & & \\
$>12$ hours & 108 & 35.1 & 102 & 53.1 & & \\
Mean \pm SD & $10.73 \pm 4.66$ & $11.70 \pm 5.01$ & 2.385 & $0.017 \mathrm{~S}$ \\
\hline
\end{tabular}

\section{DISCUSSION}

This study determines the relationship between cervical dilatation at initial presentation with the subsequent course of labour. In the present study it was observed that 20-24 years age groups were predominant in both groups, however the mean age was almost similar between two groups, which were $22.3 \pm 3.4$ years and $23.2 \pm 6.6$ years in group I and group II respectively. The mean gestational age $(39.1 \pm 1.16$ weeks in group I and $38.9 \pm 1.1$ weeks in group II) was almost similar. Bailit JL et al. (2005) have shown in their series that the mean age was $24.7 \pm$ 5.6 years in latent labor group and $24.7 \pm 5.3$ years in active labor group, which is similar with the present study ${ }^{6}$. The above authors also observed comparable mean gestational age which was 39.6 weeks in latent labor group and 39.6 weeks in active labor group and thus support the present study. Rahnama S, Ziaei $\mathrm{P}$ and Fghihzadeh 5 observed identical mean age of the patients, which was $24.25 \pm 3.3$ years in group I and $24.05 \pm 3.1$ years in group II, thus closely resemble with the present study ${ }^{7}$. 
In the current study it was observed that the mean duration of lower abdominal pain before hospitalization was significantly higher $(\mathrm{p}<0.05)$ in group II which was $10.73 \pm 4.36$ hours in group I and $11.70 \pm 5.01$ hours in group II. Holmes $\mathrm{P}$ et al. (2001) 24 observed that women presenting at 0-3 cm spent less time at home in labour before their first vaginal examination. The mean duration of first stage of labor was significantly higher $(\mathrm{p}<0.05)$ in group I which was $17.1 \pm 4.9$ hours and $14.8 \pm 3.7$ hours in group I and group II respectively. Holmes P et al. study also reflect that length of labour hour is more in women present at $0-3 \mathrm{~cm}$ than those presented at $4-10 \mathrm{~cm}^{8}$. Regarding the augmentation with oxytocin was significantly $(\mathrm{p}<0.05)$ higher in group I with compared to group II, which was $133(70.0 \%)$ in group I and $57(30.0 \%)$ in group II. Jennifer et al. supported it and concluded that early admitted group is associated with increased rate of augmentation with oxytocin? Bailit JL et al. (found in their study that latent phase women had more cesarean deliveries (nulliparas $14.2 \%$ compared with 6.7\%. Rahnama S, Ziaei P and Fghihzadeh S also found that number of caesarean delivery greater in group I than group $\mathrm{II}^{6-7}$. Majority of caesarean section in our series was done due to dystocia (Failure to progress), cephalopelvic disproportion, malposition and found $58.6 \%$ in group I and $37.5 \%$ in group II. Holmes P et al. (2001) observed that caesarean section was done due to dystocia was $50.3 \%$ in group I and $40.0 \%$ in group II, which is almost similar with the presents study ${ }^{8}$. Jackson et al. study suggest that early admission in most cases increased the risk of assisted and cesarean delivery ${ }^{10}$. Gifford et at. study shown that lack of progress was a reason for $86 \%$ of unplanned, vertex caesarians ${ }^{11}$.
Mean weight of the new born was $2.9 \pm 0.4 \mathrm{~kg}$ and $3.1 \pm 0.2 \mathrm{~kg}$ in group I and group II respectively and no significant difference was found between two groups. Apgar score was $<7$ in $72.3 \%$ in group I and $27.7 \%$ in group II at 5 minutes and the difference was statistically significant $(\mathrm{p}<0.05)$. Maghoma et al. in his study found that prolonged labour required more oxytocic drugs, more caesarean section and poor fetal outcome ${ }^{12}$.

The women presenting early did have significantly longer labour, both in nulliparous and multiparous women, but they spent less time at home before presentation, with a smaller proportion of the labour at home, than women who presented late. In addition there is evidence that the longer the labour is perceived to be by the physician, the higher the chances of intervention

Potential limitations of this study include the absence of data to determine psychological difference between women admitted in early or late in labour.

\section{CONCLUSION}

Women admitted in latent phase of labour are more likely to have prolonged labour, increased need for analgesia and subsequently increased need for caesarean section, compared to women admitted in active phase of labour. A randomized, prospective trial will be necessary to definitively persuade this observation.

\section{DISCLOSURE}

All the authors declared no competing interest.

\section{REFERENCES}

1. Archie CL, biswas manoj K. The course and conduct of normal labour and delivery, Current obstetric and Gynaecologic diagnosis and treatment, 9th ed, McGraw-Hill Companies; 2003; 213-221.

2. Calder AA. Normal labor, Dewhurst's textbook of Obstetrics and Gynaecology for potgraduates, 6th ed, Blackwell Science Ltd; 1999; 242-251.

3. Johanson R. Malposition, malpresentation and cepnalopelvic disproportion, Dewhurst's textbook of Obstetrics' and Gynecology for postgraduates 6th ed, Blackwell Science Ltd;1999; 277-289.

4. Holmes P, Oppenheimer LW, Wen SW. 'The relationship between cervical dilatation at initial presentation in labour and subsequent intervention, Br J Obstet Gynaecol, 2001;108(11: 1120-1124.

5. Melmed H, Evans M. 'Predictive value of cervical dilatation rate' B.J of Obstet and Gynaecol, 1976.

6. Gifford DS, Morton SC, Fiske M, Keesey J, Keeleer E and Kahn KL. Lack of progress in labor as a Reason for cesarean. Obstetrics and Gynecology, 2000;95(4):589-595.

7. Bailit JL, Dierker L, Blanchard HM and Mercer BM. Outcomes of women presenting in active versus latent phase of spontaneous labour. The American college of obstetricians and gynecologists, 2005;105:77-79

8. Rahman T. A prospective study on the relationship between cervical dilatation at initial presentation in labour and subsequent outcome. BCPS. 2007

9. World Health Organization. Manual of partogram WHO/MCH/1998;8.4

10. Jackson DJ, Lang JM, Ecker J, Swartz WH, Heern T. Impact of collaborative management and early admission in labor on method of delivery. JOGNN 2003;32:147-157.

11. Stewart P, Dulberg C, Chapaman. Diagnosis of dystocia and management with cesarean section among primiparous women in Ottawa-Carleton. Can Med Assoc J, 1990; 142(5):459-463.

12. Maghoma J, Buchmann EJ. Maternal and fetal risk factor associated with prolonged latent phase of labour. Br J Obstet Gynaecol 2002;22(1):16-19. 